\title{
Wither Clinical Medicine, Enter Technology!
}

\author{
Nicholas A. Antao ${ }^{1}$
}

C Indian Orthopaedics Association 2020

The physician treats with words; within the physicianpatient social system, the patient is moved by fears and other sentiments, and these are modified by the physician's words and phrases. Physicians dispense not only medicines but words that influence medicines or, all by themselves, that affect the patient more than the medicine.

$$
\text { - Dr. Morgan Martin. }
$$

Nowadays, many students when asked to take a history and clinically examine the patient, often first look at the MRI report and then scribble few lines of incomplete history and improper clinical examination. They somehow do not seem to enjoy the real inner satisfaction of matching their clinical diagnosis to the imaging studies. Observing the patient walk in your consulting room, and getting a thorough story of the patient's event and disability should help to build up a hypothesis, which then must be used either to confirm or reject your information of the patient problem.

I often, get that inner joy when my clinical diagnosis is matched with the imaging studies. Often, my students are amazed when I tell them about my provisional diagnosis as I observe the patient walk in and lie down and move the part affected to show the function, and then examine in detail to make my final diagnosis. If my diagnosis does not match the imaging study, I will again listen to the history, clinically reexamine the patient, and evaluate again to decide whether the MRI diagnosis is making sense of the issues of the problem. Remember how many times, you see in the knee non-symptomatic ACL strain, intrasubstance meniscus tear, not reaching the articular, asymptomatic labral lesions and cuff tears in the shoulder, disk degenerations and disk herniations, in normal people and prevalence of abnormal hip findings in asymptomatic non-athletes. We are here to treat the anxious patient and his problem, and not the MRI. He

Nicholas A. Antao

narantao@gmail.com

1 Department of Orthopaedics, Holy Spirit Hospital, Mahakalli Road, Andheri(E), Mumbai, Maharashtra 400093, India comes to you with the deep faith that you will help solve the problem and often completely surrenders to your counsel. I am often amazed at my patients who wait in the busy general OPD for hours, and say doctor we saw you, you heard us and you touched us and half our ailments have disappeared.

"A good physician treats the disease, the great physician treats the patient who has the disease." Unknown.

I once saw a patient for a backache. She had gone to a number of doctors with no relief of her pain. I then proceeded to take a detailed history of her back problem. On questioning whether she had ever undergone any surgery, she said yes and became very emotional and acknowledged that she had undergone an abortion. The pain in the back had started from that day she reported. To my mind, it seemed she was still struggling with the guilt related to the termination of her pregnancy. It took me a long time to counsel and reassure her on the possible psychological origin of her skeleto muscular pain. She thanked me immensely and her teary face was transformed with a smile. Needless to say, there was nothing of significance in the clinical examination and imaging studies. This case signifies the relevance of detailed history taking and clinical examination, and importantly, the doctor has to treat the patient non-judgementally as a whole human being rather than a spare part. With the recent trend of super specialities in orthopaedics, we must be cautious not to run the risk of excluding to see the patient as a whole where emotions also can play a significant role.

Having been seen, heard and examined in detail to correlate the findings, is what the patient or you and I (as the patient) would like to consider the most important service from the doctor, rather than seeing the reports and advising.

Remember that as history taking and physical examination take a back seat, and reliance upon too much technology grows, the doctor-patient relationship takes a hit and medicine may soon lose its title of the profession with a the healing touch.

To recall the words of Albert Einstein "I fear the day that technology will surpass our human interaction. The world will have a generation of idiots." 


\section{Compliance with Ethical Standards}

Conflict of interest The authors declare that they have no conflict of interest.

Ethical standard statement This article does not contain any studies with human or animal subjects performed by the any of the authors.
Informed consent For this type of study, informed consent is not required.

Publisher's Note Springer Nature remains neutral with regard to jurisdictional claims in published maps and institutional affiliations. 